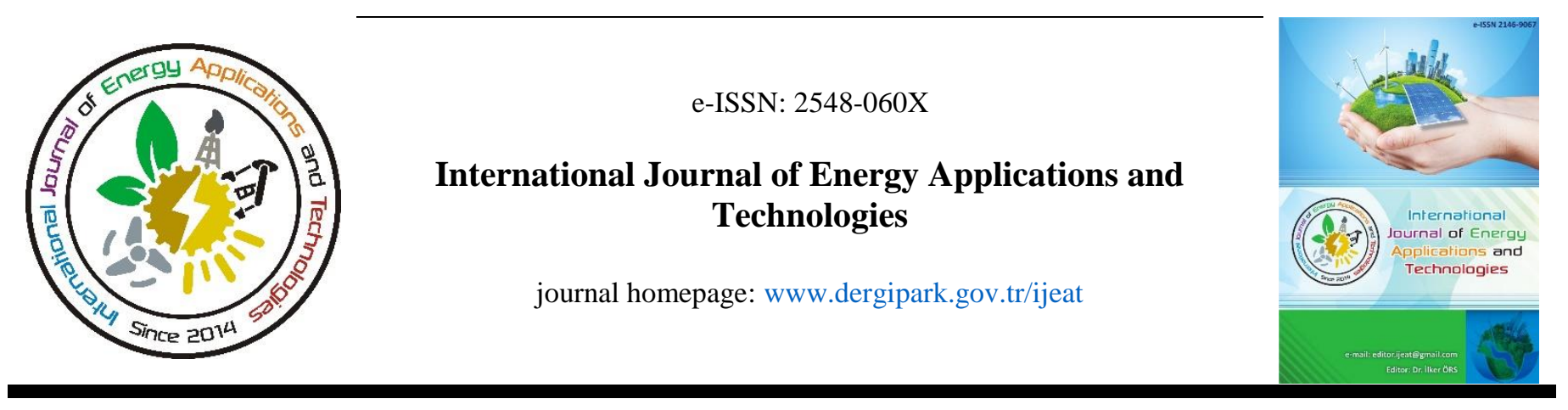

Original Research Article

\title{
Particle mass and gaseous emissions from small scale modern wood stoves
}

\author{
M. Obaidullah ${ }^{1,2^{*}}$, S. Bram ${ }^{2}$, J. De Ruyck ${ }^{2}$ \\ ${ }^{1}$ Centre for Energy Studies, Bangladesh University of Engineering and Technology, Dhaka, BANGLADESH \\ ${ }^{2}$ Department of Mechanical Engineering, Vrije Universiteit Brussel, 1050 Brussels, BELGIUM
}

\author{
ARTICLE INFO \\ * Corresponding author \\ mobaidu196@gmail.com \\ Received January 29, 2019 \\ Accepted May 27, 2019 \\ Published by Editorial Board \\ Members of IJEAT \\ (C) This article is distributed by \\ Turk Journal Park System under \\ the CC 4.0 terms and conditions. \\ doi: 10.31593/ijeat.518973
}

\begin{abstract}
The objectives of the paper were to evaluate particle mass concentrations of $\mathrm{PM}_{1}($ size $<1 \mu \mathrm{m})$ and $\mathrm{PM}_{2.5}$ (size $<2.5 \mu \mathrm{m}$ ), mass size distributions and $\mathrm{CO}$ emissions under standard laboratory conditions obtained from two commercially available modern residential wood stoves with capacity $10 \mathrm{~kW}$ and $20 \mathrm{~kW}$. Four combustion batches with minor modification of primary air flows into the combustion chamber for each stove were conducted to evaluate the emission results. Particle mass concentrations and size distributions were measured in real time using an Electrical Low Pressure Impactor Plus (ELPI+) instrument, which measures particles with a fast response time in a wide particle size range from $6 \mathrm{~nm}$ to $10 \mu \mathrm{m}$ aerodynamic diameter. Gaseous concentrations of $\mathrm{O}_{2}$ and $\mathrm{CO}_{2}$ were measured continuously using a Horiba PG-250 analyzer and $\mathrm{CO}$ emissions were measured using a Siemens Ultramat 6 gas analyzer. The measurement protocols of each combustion test were conducted according to the European standard EN 13229. The combustion experiments were conducted in a laboratory of a stove manufacturing plant in Belgium. The results showed that $\mathrm{PM}_{1}$ and $\mathrm{PM}_{2.5}$ concentrations of all the batches of both stoves varied from 116 to $327 \mathrm{mg} / \mathrm{Nm}^{3}$ and 139 to $413 \mathrm{mg} / \mathrm{Nm}^{3}$, respectively in the combustion cycle. Particle mass size distribution for all batches from both stoves is very similar showing a maximum in the fine mode at a particle size of around $330 \mathrm{~nm}$ to $500 \mathrm{~nm}$. The CO emissions from all the batches varied from 447 to $1184 \mathrm{mg} / \mathrm{Nm}^{3}$ for the $10 \mathrm{~kW}$ stove and 958 to $1545 \mathrm{mg} / \mathrm{Nm}^{3}$ for the $20 \mathrm{~kW}$ stove. The experimental results of $\mathrm{PM}_{1}, \mathrm{PM}_{2.5}$ concentrations and $\mathrm{CO}$ emissions from combustion measurements could be useful for the improvement of the combustion process as well as the reduction of gaseous and particle mass emissions from these residential biomass combustion appliances.
\end{abstract}

Keywords: particle mass concentrations; $\mathrm{PM}_{1} ; \mathrm{PM}_{2.5}$; mass size distributions; $\mathrm{CO}$ emissions

\section{Introduction}

Biomass fuels are widely available across the globe and provide a major share of renewable energy in most countries. The combustion of biomass fuels can result in a broad range of potential pollutants. Emissions from biomass combustion can be classified into two groups, which are gaseous emissions and particle emissions [1-4]. The gaseous emissions are the main gas compounds $\left(\mathrm{CO}_{2}, \mathrm{H}_{2} \mathrm{O}\right.$ and $\left.\mathrm{O}_{2}\right)$, carbon monoxide (CO), partially combusted hydrocarbons (CxHy or OGC), sulphur dioxide $\left(\mathrm{SO}_{2}\right)$, nitrogen oxides
(NOx), etc [2, 5]. Besides gaseous emissions, particulate matter (PM) emissions are always observed during biomass combustion. Particles can be divided into two groups according to their size $[2,6,7]$. These are fine particles and coarse particles. Particles smaller than $1 \mu \mathrm{m}$ (micro meter) in diameter are often called fine particles. These fine particles are generally formed from elements that are vaporized during combustion, which later saturate and form fine particles by nucleation. The nucleated particles grow further by coagulation, agglomeration, condensation and surface reaction. Particles larger than $1 \mu \mathrm{m}$ in diameter are often 
called coarse particles, forming mainly from char or ash species with low vapour pressures which do not vaporize during combustion $[2,4,7]$.

There is lack of information regarding the characterization of particulate and gaseous emissions from small scale biomass combustion appliances. Several studies on particle emissions from biomass stoves were carried out in EU countries. For example, Boman et al. [8] investigated six types of different pellet fuels in three different commercial pellet burners (10$15 \mathrm{~kW})$ and observed that fine particles $(<1 \mu \mathrm{m})$ were found a significant amount of the total PM emissions. Bäfver et al. [9] experimentally studied particle mass and $\mathrm{CO}$ emissions from modern and old type residential stoves of various heat capacity fired with wood logs and wood pellets. Measurements were performed using a Dekati Low Pressure Impactor (DLPI) for mass size distributions. Modern pellets stoves showed lower mass concentrations of particles as well as lower CO concentrations than the old type wood stoves. Qie et al. [10] studied particle emissions in a small scale pellet boiler $(50 \mathrm{~kW})$ using a Dust Trak-II Handheld Aerosol Monitor from $100 \mathrm{~nm}$ to $10 \mu \mathrm{m}$. Three types of biomass pellets, i.e. wood pellets, Miscanthus pellets and straw pellets were combusted. PM concentrations results showed that wood pellets as biomass fuel are better than Miscanthus and straw pellets. However, limited information regarding particle mass concentrations and gaseous emissions from small scale biomass combustion appliances is available in the literature.

There is a need for more scientific information of particulate matter concentrations and gaseous emissions from small scale application of wood stoves. The objectives of this paper were to evaluate experimentally particle mass concentrations, particle mass size distributions and gaseous emissions from two commercially available modern wood stoves with a capacity $10 \mathrm{~kW}$ and $20 \mathrm{~kW}$, respectively. The work includes particle mass concentrations of $\mathrm{PM}_{1}, \mathrm{PM}_{2.5}$ and $\mathrm{CO}$ emissions from the combustion cycle as well as comparison with previously reported data.

\section{Materials and Methods}

\subsection{Fuel characteristics}

The dimension of the wood $\log$ fuel was about $33 \mathrm{~cm}$ in length and $10 \mathrm{~cm}$ in diameter and the mass of each wood logs was about $1.15 \mathrm{~kg}$. The wood $\log$ was Beech species available in the Belgian forest. The chemical composition of the fuels was tested in the laboratory of SGS Environmental Services, Arnhem, the Netherlands. The elemental composition of the wood log fuel used in the combustion experiments was $43.8 \%$ carbon, $4.8 \%$ hydrogen, $38.3 \%$ oxygen, moisture $13 \%$ and the lower heating value was 16.2 $\mathrm{MJ} / \mathrm{kg}$.

\subsection{Combustion wood stoves}

The combustion appliances used in the experiments were two different commercially available Belgian made modern wood stoves of $10 \mathrm{~kW}$ and $20 \mathrm{~kW}$ heat output, respectively. The volume of the combustion chamber is $0.090 \mathrm{~m}^{3}$ for the $10 \mathrm{~kW}$ stove and $0.175 \mathrm{~m}^{3}$ for the $20 \mathrm{~kW}$ stove. The flame is directed upwards and can be seen from the outside of the stoves, since the front side of the stoves has a transparent glass window. The top surface of the combustion chamber is equipped with a baffle plate made of vermiculite having high temperature insulation material. The other sides of the combustion chamber are insulated with refractory ceramic bricks made of calcium silicate. Both stoves have the advantages of two staged combustion with supplying of primary and secondary air. Figure 1 shows a photo of the both stoves together with the combustion chamber configuration.
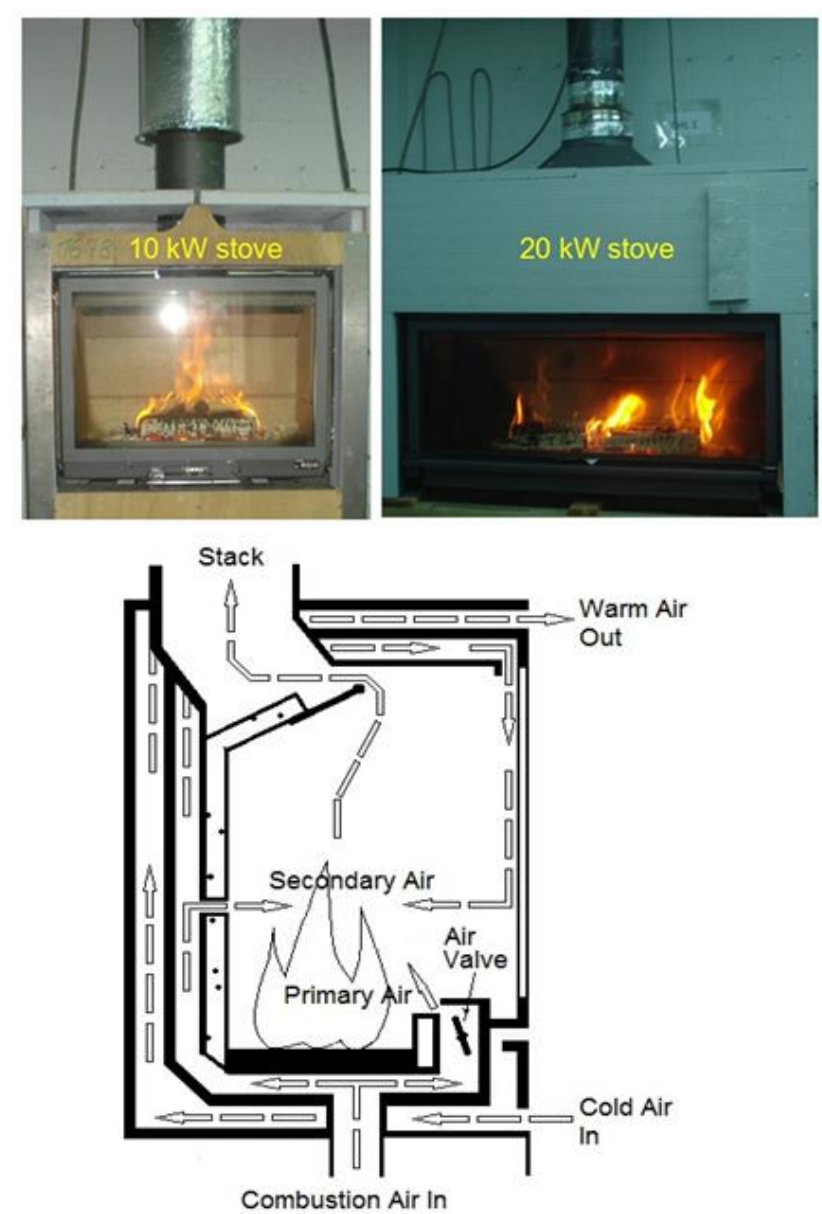

Fig. 1. Photo of $10 \mathrm{~kW}$ stove (top left), $20 \mathrm{~kW}$ stove (top right) and combustion chamber configuration with air flow pattern (bottom) used in the experiments [11]

\subsection{Experimental setup}

The experimental setup for the particle mass and gaseous emission measurements is shown in Figure 2. The measurement protocols of each combustion test were conducted according to the European standard EN 13229 
[12]. For each stove, measurements were repeated for several batches with minor modification of primary air flows into the combustion chamber to evaluate the emissions results.

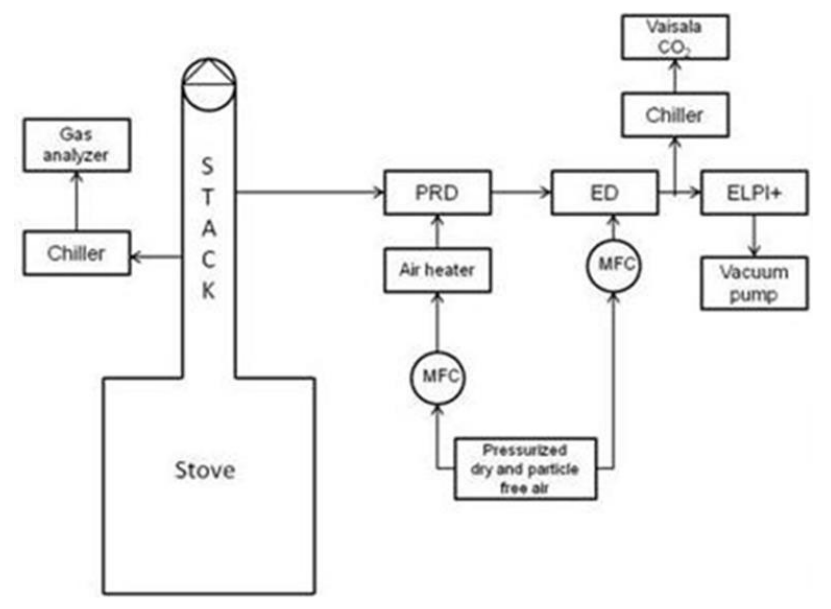

(a)

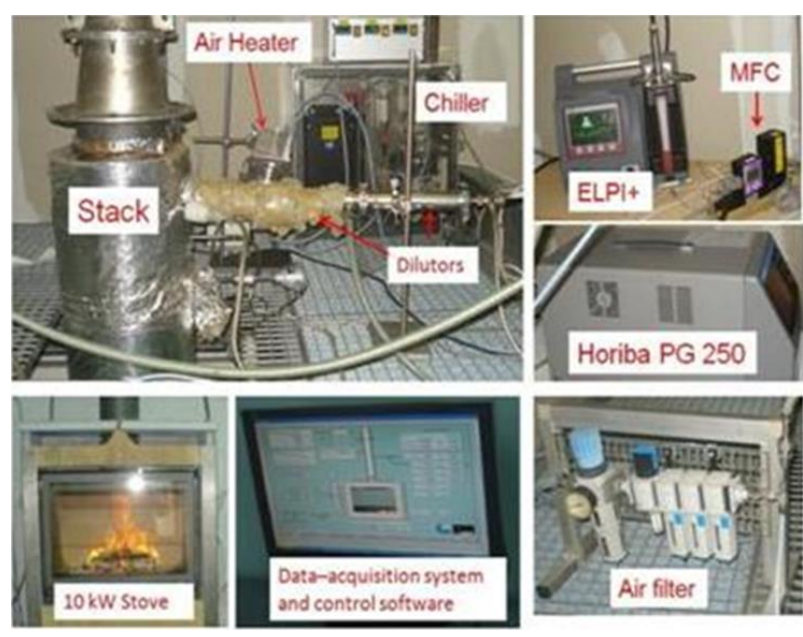

(b)

Fig. 2. Experim. setup for emission measurements from wood stoves (a) schematic of the setup, , PRD = Porous tube dilutor, ED =Ejector dilutor, $\mathrm{MFC}=$ Mass flow controller, ELPI $+=$ Electrical Low Pressure Impactor Plus, (b) some photos of the measurements

\subsection{Particle emissions measurements}

Particle mass concentrations were measured in real time using an Electrical Low Pressure Impactor Plus (ELPI+) from Dekati Ltd., Finland. It measures particles with a fast response time in a wide particle size range from $6 \mathrm{~nm}$ to 10 $\mu \mathrm{m}$ aerodynamic diameter. A partial flow from the stack about $1.8 \mathrm{~m}$ above the wood stoves was led through an externally insulated bent tube probe which was made of 12 $\mathrm{mm}$ (diameter) stainless steel. The flue gases were passed through a partial flow dilution tunnel before reaching the particle measuring instrument, the ELPI+. The dilution tunnel consists of a porous tube diluter (PRD), an ejector diluter (ED) and an air heater. The working principle of the ELPI+, the measurement procedures of dilution air flows and the calculation of dilution ratio (DR) are discussed in the work $[1,6,13,14]$.

\subsection{Gaseous emissions measurements}

Gaseous concentrations of $\mathrm{O}_{2}$ and $\mathrm{CO}_{2}$ were measured continuously using a Horiba PG-250 analyzer and CO emissions were measured using a Siemens Ultramat 6 gas analyzer. The measurement principles of the gas analysers were galvanic analyzer for $\mathrm{O}_{2}$ and non-dispersive infrared for $\mathrm{CO}$ and $\mathrm{CO}_{2}$. The raw flue gases were sampled by the steel probes from the stack at about $1.8 \mathrm{~m}$ above the stoves.

\section{Results and Discussions}

Emissions from residential biomass combustion are considered as a major contributor to ambient air pollution. The combustion experiments were performed from two commercially available modern wood stoves with a capacity $10 \mathrm{~kW}$ and $20 \mathrm{~kW}$, respectively at the combustion laboratory of a stove manufacturing plant in Belgium. Particle mass concentrations, mass size distributions and gaseous emission measurements were conducted for four combustion batches for each wood stove under standard laboratory condition. The particle mass concentrations and $\mathrm{CO}$ emissions in this paper is defined as the amount of particle mass and $\mathrm{CO}$ emissions from the startup and combustion phases. The particle mass $\mathrm{PM}_{1}, \mathrm{PM}_{2.5}$ concentrations and gaseous emissions are presented in Table 1. Since the combustion process varies significantly over time in the batch fired heating appliances, the presented standard deviation $( \pm)$ also describes the variation of the process.

\subsection{Particle mass concentrations}

The flue gas velocities in the stack of the $10 \mathrm{~kW}$ and $20 \mathrm{~kW}$ wood stoves were $0.47 \mathrm{~m} / \mathrm{s}$ and $0.65 \mathrm{~m} / \mathrm{s}$, respectively. The flue gas velocity in the nozzle was about $0.29 \mathrm{~m} / \mathrm{s}$. This means that the PM measurements are sub-isokinetic and therefore $\mathrm{PM}_{10}$ concentrations are not included in this paper as the present work puts emphasizing on the very small particles.

Particles collected on the aluminum subtraces of the impactor stages of the ELPI+ range from $6 \mathrm{~nm}$ to $10 \mu \mathrm{m}$ aerodynamic diameter are shown in Figure 3. It can be seen from the figure that the black particles on the impactor stages are the fine particle deposition obtained from the Batch 2 of $10 \mathrm{~kW}$ wood stove. These particles are mostly fine particles formed from elements that are vaporized during combustion, which later saturate and form fine particles by nucleation. The nucleated particles grow further by coagulation, agglomeration, condensation and surface reaction. The fine particles are mainly formed of potassium salts such as $\mathrm{K}_{2} \mathrm{SO}_{4}$ (potassium sulphate), $\mathrm{KCl}$ (potassium chloride), $\mathrm{K}_{2} \mathrm{CO}_{3}$ (potassium carbonate) and smaller amounts of zinc, sodium and organic material $[2,5,8]$. 
Table 1. Average $\mathrm{O}_{2}, \mathrm{CO}_{2}$, and $\mathrm{CO}$ emissions measured by the gas analyzers, $\mathrm{PM}_{1}$ and $\mathrm{PM}_{2.5}$ concentrations measured by the ELPI+ obtained from the $10 \mathrm{~kW}$ and $20 \mathrm{~kW}$ wood stoves

\begin{tabular}{|c|c|c|c|c|c|c|c|c|}
\hline \multirow{2}{*}{ Particulars } & \multicolumn{4}{|c|}{$10 \mathrm{~kW}$ stove } & \multicolumn{4}{|c|}{$10 \mathrm{~kW}$ stove } \\
\hline & Batch 1 & Batch 2 & Batch 3 & Batch 4 & Batch 1 & Batch 2 & Batch 3 & Batch 4 \\
\hline $\begin{array}{l}\text { Duration } \\
(\mathrm{min}: \mathrm{sec})\end{array}$ & $45: 30$ & $41: 45$ & $40: 15$ & $47: 15$ & $51: 00$ & $48: 15$ & 43:00 & $51: 30$ \\
\hline $\begin{array}{l}\mathrm{O}_{2} \\
\text { (vol. \%) }\end{array}$ & $9.7 \pm 0.8$ & $8.1 \pm 0.7$ & $8.3 \pm 0.7$ & $9.7 \pm 0.6$ & $11.0 \pm 0.5$ & $10.7 \pm 0.6$ & $9.9 \pm 0.6$ & $10.8 \pm 0.5$ \\
\hline $\mathrm{CO}_{2}$ (vol. \%) & $10.6 \pm 0.8$ & $12.0 \pm 0.7$ & $12.3 \pm 0.7$ & $10.7 \pm 0.7$ & $9.2 \pm 0.6$ & $9.4 \pm 0.6$ & $10.3 \pm 0.7$ & $9.5 \pm 0.5$ \\
\hline $\begin{array}{l}\text { Stack Temp } \\
\left({ }^{\circ} \mathrm{C}\right)\end{array}$ & $288 \pm 15$ & $301 \pm 11$ & $305 \pm 7$ & $292 \pm 4$ & $289 \pm 11$ & $294 \pm 12$ & $319 \pm 7$ & $279 \pm 4$ \\
\hline Excess air $(\lambda)$ & 1.86 & 1.64 & 1.66 & 1.87 & 2.12 & 2.06 & 1.99 & 2.12 \\
\hline $\begin{array}{l}\mathrm{CO} \text { in } 13 \% \\
\mathrm{O}_{2}\left(\mathrm{mg} / \mathrm{Nm}^{3}\right)\end{array}$ & $1095 \pm 217$ & $1184 \pm 251$ & $447 \pm 123$ & $508 \pm 131$ & $1545 \pm 205$ & $1338 \pm 180$ & $958 \pm 157$ & $1255 \pm 152$ \\
\hline Dilution ratio & $35.5 \pm 3.4$ & $37.8 \pm 2.8$ & $40.9 \pm 2.2$ & $34.3 \pm 1.5$ & $36.9 \pm 1.7$ & $37.6 \pm 1.9$ & $37.9 \pm 1.0$ & $31.0 \pm 0.7$ \\
\hline $\begin{array}{l}\mathrm{PM}_{1} \\
\left(\mathrm{mg} / \mathrm{Nm}^{3}\right)\end{array}$ & $209 \pm 35.7$ & $295 \pm 37.7$ & $327 \pm 42.1$ & $166 \pm 25.9$ & $116 \pm 21.1$ & $135 \pm 24.1$ & $195 \pm 29.1$ & $149 \pm 21.2$ \\
\hline $\begin{array}{l}\mathrm{PM}_{2.5} \\
\left(\mathrm{mg} / \mathrm{Nm}^{3}\right)\end{array}$ & $265 \pm 57.6$ & $371 \pm 58.5$ & $413 \pm 65.3$ & $225 \pm 38.1$ & $139 \pm 37.7$ & $161 \pm 40.1$ & $279 \pm 51.9$ & $229 \pm 35.3$ \\
\hline
\end{tabular}

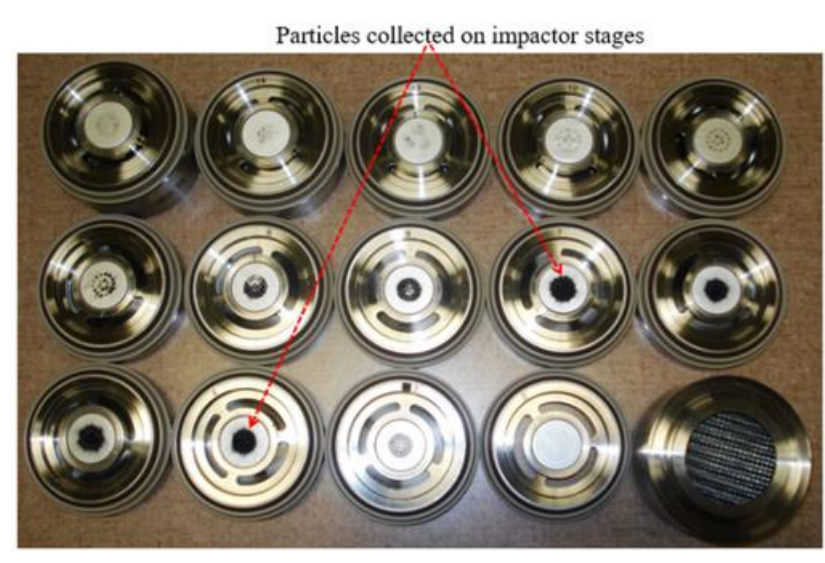

Fig. 3. Particle deposition on the aluminium subtracts of the impactor stages of the ELPI+

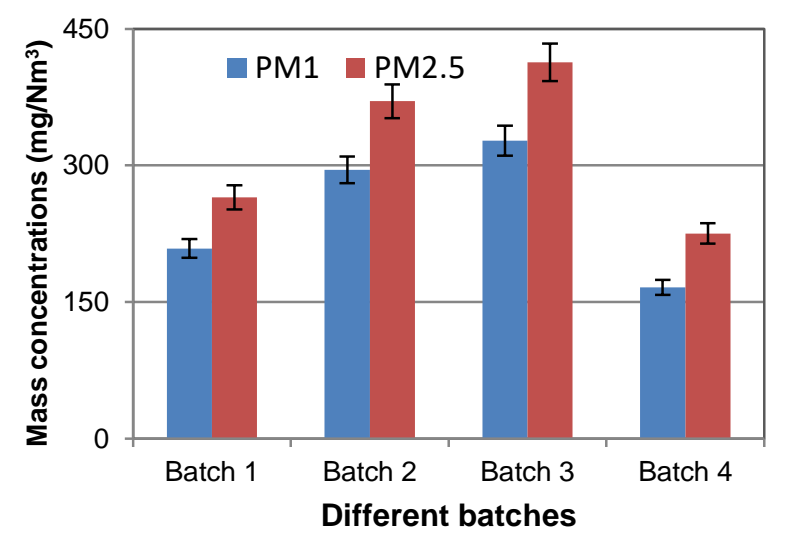

(a)
Figure 4 compares the particle mass concentrations of $\mathrm{PM}_{1}$ and $\mathrm{PM}_{2.5}$ concentrations obtained from different combustion batches of the $10 \mathrm{~kW}$ stove and $20 \mathrm{~kW}$ stove, respectively. The error bars present the uncertainty of the measurements. It is observed from the figures that $\mathrm{PM}_{1}$ concentrations of all the batches of both stoves varied from 116 to $327 \mathrm{mg} / \mathrm{Nm}^{3}$ while and $\mathrm{PM}_{2.5}$ concentrations varied between 139-413 $\mathrm{mg} / \mathrm{Nm}^{3}$. Batch 4 for the $10 \mathrm{~kW}$ stove and Batch 1 for the 20 $\mathrm{kW}$ stove emitted the lowest PM emissions in the both $\mathrm{PM}_{1}$ and $\mathrm{PM}_{2.5}$ concentrations. The mass concentrations results obtained from the combustion experiments are little high when compared to the literature $[8,10]$, which may be due to the difference of the combustion technologies, the measurement protocols and the instruments used.

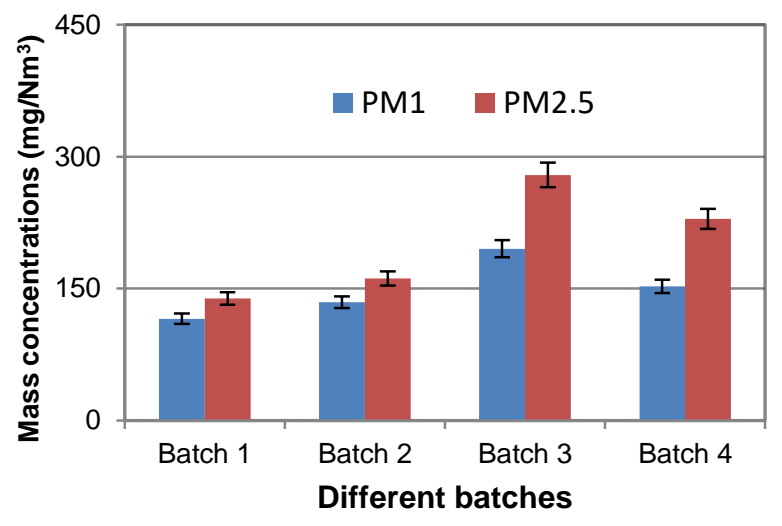

(b)

Fig. 4. $\mathrm{PM}_{1}$ and $\mathrm{PM}_{2.5}$ emissions from different batches, (a) for the $10 \mathrm{~kW}$ stove, (b) for the $20 \mathrm{~kW}$ stove

The obtained results demonstrate quite some variation in the measured $\mathrm{PM}_{1}$ and $\mathrm{PM}_{2.5}$ values over time for the different batches, which is typical for the combustion of wood log stoves. $\mathrm{PM}_{1}$ concentrations of all the batches of the $10 \mathrm{~kW}$ stove accounted for $76.8 \%$ of the $\mathrm{PM}_{2.5}$ concentrations, while $75.6 \%$ of the $20 \mathrm{~kW}$ stove, which are little lower values than the literature [8]. The $\mathrm{PM}_{1}$ and $\mathrm{PM}_{2.5}$ emissions from the $20 \mathrm{~kW}$ stove are much lower than the $10 \mathrm{~kW}$ stove. The average fuel consumption for each batch of the $10 \mathrm{~kW}$ stove is about one-half lower than the $20 \mathrm{~kW}$ stove, which might 
impact on particle mass emissions. Several studies reported that increased particle concentrations from the combustion devices in the ambient air correlate with adverse health effects in the exposed population, including respiratory and cardiovascular illnesses as well as increased mortality [1517]. Further, it has been reported in the literature that in the case of combustion related particles, the fine particle fraction is especially harmful to human health [18-20].

\subsection{Particle mass size distribution}

Figure 5 shows the particle mass size distributions obtained from the combustion experiments of the $10 \mathrm{~kW}$ and $20 \mathrm{~kW}$ stove, respectively. The abscissa represents the particle aerodynamic diameter against the ordinate which shows the ratio of particle mass concentrations $d M$ to the logarithm of the channel width $d \log (D p)$, where $D p$ is the aerodynamic diameter. It is observed from the figures that the emitted particle mass size distributions for all batches is very similar showing a maximum in the fine mode at a particle size of around $330 \mathrm{~nm}$ to $500 \mathrm{~nm}$. Particles between $10 \mathrm{~nm}$ and $100 \mathrm{~nm}$ represent a very small amount of mass, probably soot

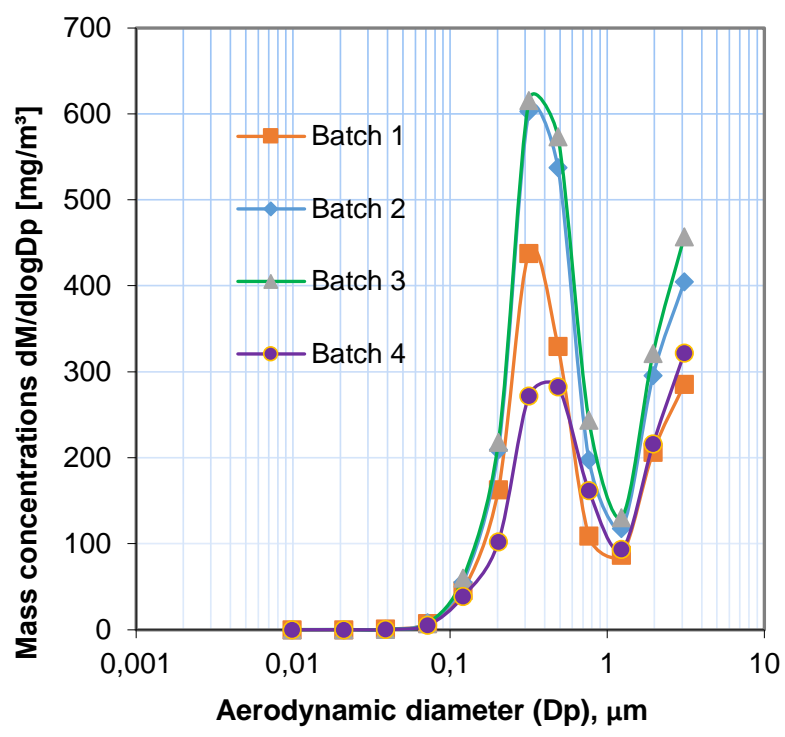

(a) particles, therefore these particles are not seen in the mass size distribution graphs. These small size particles are considered very harmful for human health as they penetrate lower the alveolar region of the lung [16, 21].

Mass size distributions obtained in our measurements can be compared with other work. For example, Bäfver et al. [9] investigated particle mass size distributions in a wood stove using a DLPI. They found that maximum particle mass concentrations were at the particle size of $400 \mathrm{~nm}$. Sippula et al. $[4,22]$ presented particle formation pathways from wood combustion where there are two types of particles. One is the fine mode, where the particles form through nucleation and condensation from the inorganic vapours. The other is the coarse mode which mainly consists of non-volatilized ash residuals and fly ash particles. Obaidullah et al. [23] investigated particle mass size distribution from a pellet stove with capacity of $5 \mathrm{~kW}$ using ELPI+ and the results show that the maximum particle concentrations in the fine mode mainly at the particle size about $320 \mathrm{~nm}$ for the start-up and combustion phase and at $300 \mathrm{~nm}$ for the burnout phase.

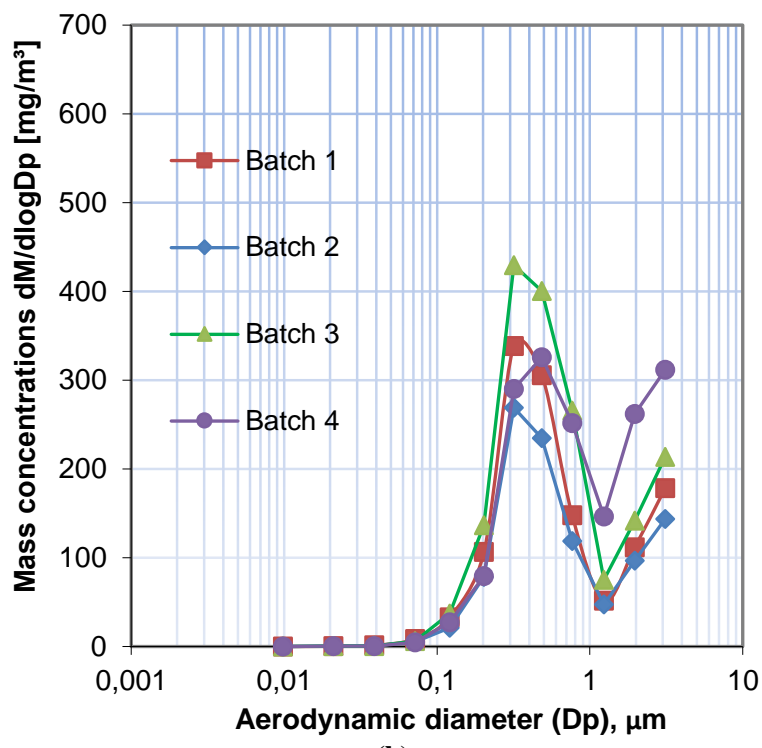

(b)

Fig. 5. Particle mass size distribution from different batches, (a) for the $10 \mathrm{~kW}$ stove, (b) for the $20 \mathrm{~kW}$ stove

\subsection{Gaseous emissions}

Generally, gaseous emissions from manually batch fired stoves are highly variable. Combustion behaviour is affected by different factors such as fuel properties, appliance type and operational practice, etc. Concentrations of $\mathrm{O}_{2}, \mathrm{CO}_{2}$ and $\mathrm{CO}$ were measured continuously were measured by the gas analyzers. The NOx emissions were not performed from the stoves because these emissions were measured by the manufacturer once during the formal pass-test. The following values were obtained $88 \mathrm{mg} / \mathrm{Nm}^{3}$ for the $10 \mathrm{~kW}$ stove and $105 \mathrm{mg} / \mathrm{Nm}^{3}$ for the $20 \mathrm{~kW}$ stove, which satisfy the European norms $\left(240 \mathrm{mg} / \mathrm{Nm}^{3}\right)$. Besides, the NOx cell of the Horiba
PG 250 analyzer was not operational. For those reasons, NOx emission measurements were not performed.

\subsection{Time series of $\mathrm{CO}_{2}, \mathrm{CO}$ and $\mathrm{O}_{2}$ concentrations}

Figure 6 shows the variations of the concentration of $\mathrm{CO}$, $\mathrm{CO}_{2}, \mathrm{O}_{2}$ and temperature of the flue gases over the measurement time during the combustion cycles of the 20 $\mathrm{kW}$ stove. The time for supplying a new batch of logwood was defined from the moment when no visible flames were observed and $\mathrm{CO}_{2}$ concentration reached about $5 \%$. Then, a batch of wood logs was supplied on the glow bed of the previous fire 


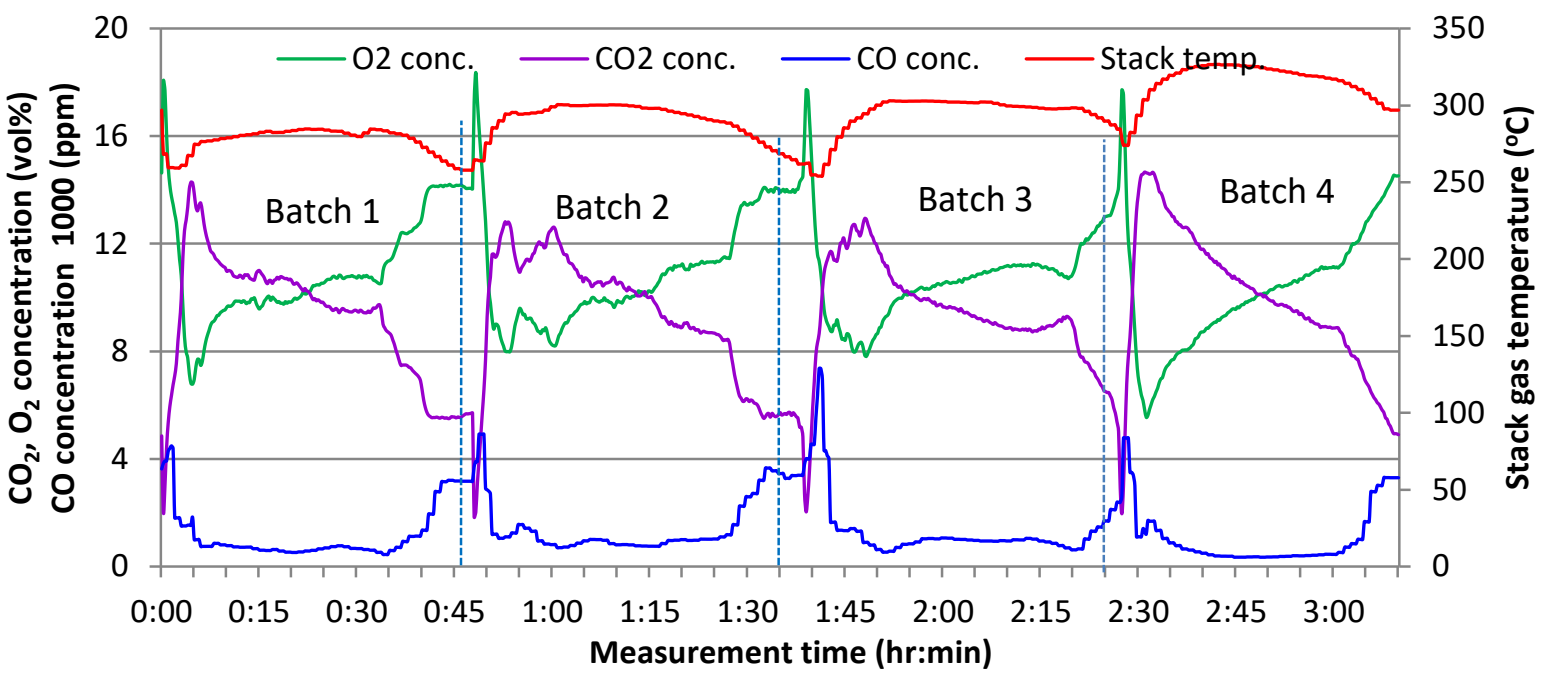

Fig. 6. Variation of gas concentrations of $\mathrm{CO}, \mathrm{CO}_{2}, \mathrm{O}_{2}$ and stack temperature measured for the $20 \mathrm{~kW}$ stove

It can be seen from the figure that at the start-up phase, the highest concentrations of $\mathrm{CO}$ and significant variations of temperature of the flue gas occur. During the combustion phase, the CO concentrations are sufficiently lower and the stack temperature is higher. In figure 6 , it is also observed that $\mathrm{O}_{2}$ concentrations increase and $\mathrm{CO}_{2}$ concentrations decrease during the combustion phases. This might be explained by the combustion of volatiles at the start of the combustion phase followed by a combustion slowdown as the fuel amount decreases.

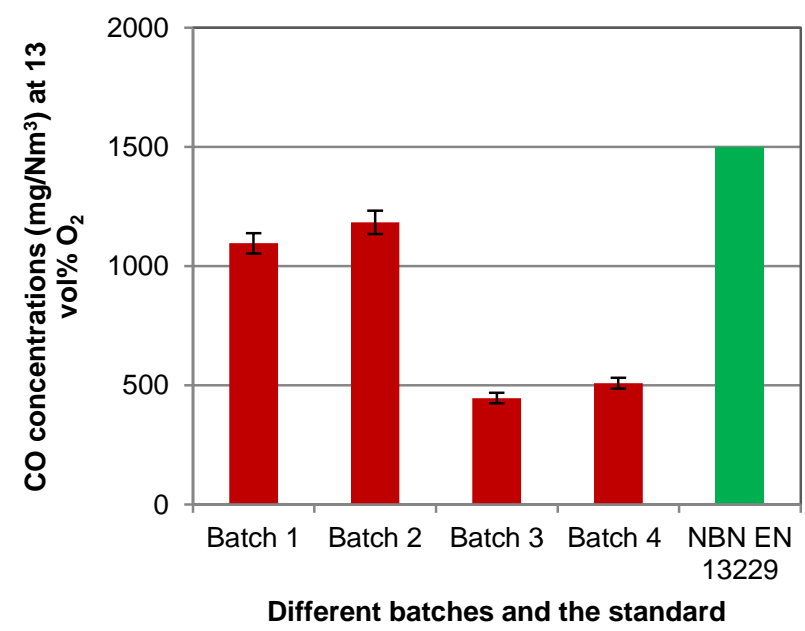

(a)

\subsection{CO emissions}

CO emissions are observed in the combustion of all carbonaceous fuels, as an intermediate product of the combustion process. It is the most important intermediate product of fuel conversion to $\mathrm{CO}_{2}$. It is oxidized to $\mathrm{CO}_{2}$ under appropriate temperature and oxygen availability and sufficient presence of $\mathrm{OH}$ radicals. Figure 7 shows the comparison of $\mathrm{CO}$ emissions obtained from all the measurements from both stoves with the required limit value of standard NBN EN 13229 [24].

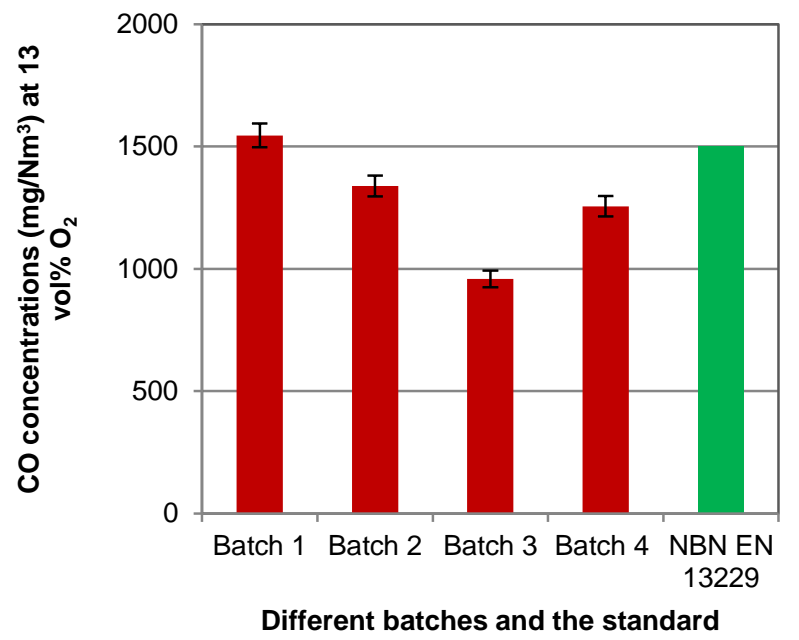

(b)

Fig. 7. Comparison of $\mathrm{CO}$ emissions with the Standard, (a) for the $10 \mathrm{~kW}$ stove, (b) for the $20 \mathrm{~kW}$ stove

The $\mathrm{CO}$ emission values presented in this paper are normalized to 13 vol \% dry oxygen content. The error bars present the uncertainties of measurements calculated as the square root of the sum of the square of the standard error of mean (SEM) and the instruments' error. Both stoves (except batch 1 of the $20 \mathrm{~kW}$ stove) satisfied the required limit value of the standard. The results show that the $\mathrm{CO}$ emissions from all the batches varied from 447 to $1184 \mathrm{mg} / \mathrm{Nm}^{3}$ for the 10 $\mathrm{kW}$ stove and 958 to $1545 \mathrm{mg} / \mathrm{Nm}^{3}$ for the $20 \mathrm{~kW}$ stove. It is observed that the $\mathrm{CO}$ emissions with the $20 \mathrm{~kW}$ stove were 
higher than the $10 \mathrm{~kW}$ stove due to the differences in combustion chamber volume, fuel consumption and heat output. The average fuel load for each batch of the $20 \mathrm{~kW}$ stove $(4.37 \mathrm{~kg} / \mathrm{batch})$ was about 2 times higher than the 10 $\mathrm{kW}$ stove $(2.19 \mathrm{~kg} / \mathrm{batch})$. This can also be discussed in other ways. The higher air excess factor $(\lambda=2.1)$ obtained in the 20 $\mathrm{kW}$ stove might have caused lower combustion temperature, leading to high $\mathrm{CO}$ emissions. On the other hand, a correctly matched air excess factor $(\lambda=1.8)$ for the $10 \mathrm{~kW}$ stove created favorable combustion conditions leading to less $\mathrm{CO}$ emissions. No correlation was observed between $\mathrm{CO}$ emissions and minor modification of primary air flows into the combustion chamber. The higher $\mathrm{CO}$ emissions indicate poorer combustion conditions since these are related with incomplete combustion. Present results of the $\mathrm{CO}$ emission are close to those reported in another study of a residential modern wood stove $[25,26]$, while quite lower than those reported in other studies of wood modern stoves [9, 27-29]. $\mathrm{CO}$ emissions from residential biomass combustion can be reduced using flue gas cleaning technologies such as catalytic combustors, which consist of a metal wire mesh covered with catalytic material, platinum and palladium. Hukkanen et al. [30] investigated reduction of gaseous emissions using a catalytic combustor from a $15 \mathrm{~kW}$ stove. Their results show that reductions of $\mathrm{CO}$ reached about $25 \%$ during the whole combustion cycle. Such gas cleaning systems are however quite expensive for small scale applications.

\section{Conclusion}

This study presents particle mass concentrations, particle mass size distributions and $\mathrm{CO}$ emissions obtained from several combustion batches of two commercially available modern wood stoves with a capacity $10 \mathrm{~kW}$ and $20 \mathrm{~kW}$, respectively. The combustion experiments were performed at the combustion laboratory of a stove manufacturing plant in Belgium. The following conclusions can be made from this study.

- The obtained particle mass concentrations results of $\mathrm{PM}_{1}$ and $\mathrm{PM}_{2.5}$ demonstrate quite variation in the measured values over time for the different batches, which is typical for the combustion of wood log stoves.

- The particle mass size distributions obtained from the both wood stoves shows that maximum particle concentrations varied between $330 \mathrm{~nm}$ and $500 \mathrm{~nm}$. It seems that the particle mass size distributions of both stoves are quite similar. These ultrafine particles are very harmful for human health as they penetrate the alveolar region of the lung.

- The CO emissions from all batches of both stoves (with exception for the Batch 1 of $20 \mathrm{~kW}$ ) satisfied the required limit value of the standard. The results of $\mathrm{CO}$ emissions from the wood stoves demonstrate the detailing characterization of certain parameters could be useful for the improvement of the entire combustion process.

- CO emissions from small scale biomass combustion appliances can be reduced using flue gas cleaning technologies such as catalytic combustors.

- The experimental results of $\mathrm{PM}_{1}, \mathrm{PM}_{2.5}$ concentrations and $\mathrm{CO}$ emissions from combustion measurements could be useful for the improvement of the combustion process as well as the reduction of gaseous and particle mass emissions from these residential biomass combustion appliances.

\section{Acknowledgements}

The authors gratefully acknowledge the support of the Erasmus Mundus External Cooperation Window (EM ECW) of the European Commission, grant agreement number 1663/001-001-ECW and the European Regional Development Fund (ERDF/EFRO), project P12-05 EMOVO. The author would like to express sincere thanks to the department MECH, VUB and the department combustion laboratory of a stove manufacturing plant, Belgium for their help in conducting the experiments and support.

\section{References}

[1] Obaidullah M. Particle Emissions from Small Scale Combustion Appliances. Brussel, Belgium: Vrije Universiteit Brussel (VUB); PhD thesis, November 2014.

[2] Obaidullah M, Bram S, Verma V, De Ruyck J. A Review on Particle Emissions from Small Scale Biomass Combustion. International Journal of Renewable Energy Research (IJRER). 2012;2:147-59.

[3] Obaidullah M, Bram S, De Ruyck J. Characteristics of Particle Mass Concentrations from Small Scale Biomass Combustion: A Review. VII International Conference on Energy and Environment for 21 Century. Las Villas, Cuba: Central University Marta Abreu (UCLV); 2012.

[4] Sippula O, Hokkinen J, Puustinen H, Yli-Pirila P, Jokiniemi J. Comparison of particle emissions from small heavy fuel oil and wood-fired boilers. Atmospheric Environment. 2009;43:4855-64.

[5] Obaidullah M, Bram S, De Ruyck J. Investigation on Gaseous and Particle Mass Emissions from Automatically Fired Small Scale Heating System Under Laboratory Conditions. International Journal of Renewable Energy Development. 2018;7:111-21.

[6] Obaidullah M, Bram S, De Ruyck J. An Overview of PM Formation Mechanisms from Residential Biomass Combustion and Instruments Using in PM Measurements. International Journal of Energy and Environment. 2018;12:41-50.

[7] Obernberger I, Brunner T, Barnthaler G. Fine particle emissions from Modern Austrian small scale biomass 
combustion plants. 15th European biomass conference and exhibition. Germany7-11 May 2007. p. 1546-57.

[8] Boman C, Nordin A, Bostrom D, Ohman M. Characterization of Inorganic Particulate Matter from Residential Combustion of Pelletized Biomass Fuels. Energy \& Fuels. 2004;18:338-48.

[9] Bäfver LS, Leckner B, Tullin C, Berntsen M. Particle emissions from pellets stoves and modern and old-type wood stoves. Biomass and Bioenergy. 2011;35:3648-55.

[10] Qiu G. Testing of flue gas emissions of a biomass pellet boiler and abatement of particle emissions. Renewable Energy. 2013;50:94-102.

[11] Stuv SA. Stuv installation instructions. 97851. Belgium 2011. p. 7.

[12] EN-13229. Open fires and inserts solid fuel Requirements and test methods. French Association Standardization; June 2002.

[13] Obaidullah M, Sarkar M, Bram S, De Ruyck J. Evaluation of Dilution Ratio from a Partial flow Dilution Tunnel. 7th IMEC \&16th Annual Paper Meet. IEB, Dhaka2-3 Jan 2015.

[14] Obaidullah M, Bram S, De Ruyck J. Investigation of Optimal Dilution Ratio from a Dilution Tunnel Using in Particulate Matter Measurement. International Journal of Engineering Technology and Sciences (IJETS). 2018;5:17-33.

[15] Kubica K, Paradiz B, Dilara P. Small combustion installation: Techniques, emissions and measure for emissions reduction. JRC Scientific and Technical Reports2007.

[16] Lighty JS, Veranth JM, Sarofim AF. Combustion Aerosols: Factors Governing Their Size and Composition and Implications to Human Health. Journal of the Air \& Waste Management Association: Taylor \& Francis; 2000. p. $1565-618$.

[17] Nussbaumer T, Klippel N, Johansson L. Survey on measurements and emission factors on particulate matter from biomass combustion in IEA countries. Proc 16 th European Biomass Conference and Exhibition2008. p. 26.

[18] Obaidullah M, Dyakov I, Peeters L, Bram S, De Ruyck J. Comparison of particle emissions from enclosed parking garages and streets. GNEST. 2013;15:457-65.

[19] Bolling AK, Pagels J, Yttri KE, Barregard L, Sallsten G, Schwarze PE, et al. Health effects of residential wood smoke particles: the importance of combustion conditions and physicochemical particle properties. Particle and fibre toxicology. 2009;6:20.

[20] Obaidullah M, Dyakov I, Peeters L, Bram S, De Ruyck J. Investigation of Particulate Matter Pollutants in Parking Garages. In: Mastorakis $\mathrm{N}$, editor. Latest advancement in Biology, Environment and Ecology. G. Enescu University, Iasi, Romania: WSEAS and NAUN Press; 2012. p. 105-10.

[21] Obaidullah M, Dyakov I, Peeters L, Bram S, De Ruyck J. Measurements of Particle Concentrations and Size Distributions in Three Parking Garages. International journal of energy and environment. 2012;6:508-15.
[22] Sippula O. Fine particle formation and emission in biomass combustion [Ph. D]. Finland: University of Eastern Finland; 2010.

[23] Obaidullah M, Bram S, De Ruyck J. Measurements of Particle Emissions and Size Distributions from a Modern Residential Pellet Stove under Laboratory Conditions. International Journal of Systems Applications, Engineering \& Development 2019;13:1-9.

[24] Royal-Decree, Belgium. Regulating the minimum efficiency requirements and emission levels of pollutants heaters with solid fuels. October 2010, (available at http://environnement.wallonie.be/legis/air/air064.htm ).

[25] Roy MM, Corscadden KW. An experimental study of combustion and emissions of biomass briquettes in a domestic wood stove. Applied Energy. 2012;99:206-12.

[26] Obaidullah M, Bram S, Thomassin JD, Duquesne T, Dyakov IV, Contino F, et al. CO Emission Measurements and Performance Analysis of $10 \mathrm{~kW}$ and $20 \mathrm{~kW}$ Wood Stoves. Energy Procedia. 2014;61:2301-6.

[27] Pettersson Er, Boman C, Westerholm R, Bostrom D, Nordin A. Stove Performance and Emission Characteristics in Residential Wood Log and Pellet Combustion, Part 2: Wood Stove. Energy \& Fuels. 2011;25:315-23.

[28] Schmidl C, Luisser M, Padouvas E, Lasselsberger L, Rzaca M, Ramirez-Santa Cruz C, et al. Particulate and gaseous emissions from manually and automatically fired small scale combustion systems. Atmospheric Environment. 2011;45:7443-54.

[29] Koyuncu T, Pinar Y. The emissions from a spaceheating biomass stove. Biomass and Bioenergy. 2007;31:73-9.

[30] Hukkanen A, Kaivosoja T, Sippula O, Nuutinen K, Jokiniemi J, Tissari J. Reduction of gaseous and particulate emissions from small-scale wood combustion with a catalytic combustor. Atmospheric Environment. 2012. 